\title{
DA DIALÉTICA DO ADMIRAR E DO PERGUNTAR
}

Sérgio A. Sardi*

SÍNTESE - O texto visa contribuir, por um lado, à investigação acerca dos processos psicológicos, aos niveis subjetivo, lógico e intersubjetivo, inerentes a uma postura filosofante, remetendo a considerações metodológicas com relação ao ensino de Filosofia. Por outro, visa questionar a relação entre o filosofar e a História da Filosofia, visando à conexão entre 0 diálogo filosófico e 0 diálogo com a História da Filosofia.

\begin{abstract}
The text intends, first of all, to contribute to the investigation about the psychological processes in subjective, logical and intersubjective levels inherent in a philosophical attitude; moreover it sends to methodological considerations related to the teaching of philosophy. Secondly, it aims to discuss the relation between the act of making philosophy and the history of philosophy, having in mind the connection between the philosophical dialogue and the dialogue with the history of philosophy.
\end{abstract}

\section{1 - Admirar}

Convido-te à reflexão: presta, pois, atenção ao que acontece contigo mesmo, à tua Presença no mundo. Talvez não tenhas em mente, no entanto, neste momento, a sensação de teus próprios pés, tocando o chão, as costas em contato com a cadeira ou porventura um som, ao longe, o qual, se estiveres atento, perceberás. Dirige, então, a atenção às múltiplas sensações que afetam o teu corpo e perceberás que, a cada instante, parece haver uma certa distância entre aquilo que o teu corpo sente e a consciência deste sentir. Descobrirás, assim, uma intenção em teu contato com o mundo, uma atividade do teu pensamento que seleciona aquilo que, neste momento, interessa à tua atenção.

Retém a atenção nesta atividade mesma de teu pensamento... pensando em teu pensamento... vivenciando o mistério e o estranhamento de perceber-se insondável por si mesmo: estarás em ti e, simultaneamente, além, ou aquém... nos desejos, na memória que não dominas, na angústia inexplicável, neste fundo cria-

Professor do Instituto de Filosofia e Ciências Humanas da PUCRS e doutorando em Filosofia pela Unicamp/SP.

\begin{tabular}{|l|l|l|l|l|l|}
\hline VERITAS & Porto Alegre & v. 42 & $\mathrm{n}^{\circ} 4$ & Dezembro 1997 & p. 931-936 \\
\hline
\end{tabular}


dor que vive em ti... profundamente em ti e, aparentemente, além de ti mesmo: motivo de espanto? Sim, motivo de uma admiração com teu próprio ser.

Dirige, agora, tua atenção para uma realidade qualquer, a qual já tenhas visto muitas e muitas vezes sem, no entanto, ter tido a oportunidade de observá-la de um modo novo, inusitado. Talvez à tua própria mão, e ao que acontece em seu interior, que vives e não sabes; ao fato de seres feito de carne, esta matéria tão especial quanto misteriosa; ao fato de participares da vida. Ou, talvez ainda, possas centrar tua atenção neste texto, o qual tens em mãos. Um papel e marcas a tinta; marcas que fazem o teu pensamento mover-se de um modo determinado; comunico-me assim contigo e, de algum modo, compreendes o que eu digo, através deste objeto, destas marcas. Algo, pois, evidentemente, está em mim, está em ti, está no papel... e é o mesmo, ou nada poderia te comunicar. Mas há algo, também, que sobrepassa esta identidade, na minha intenção, na tua interpretação. Por outro lado, percebe, não são as palavras que escrevo, elas mesmas, que te fazem compreender o que te digo; mas o fato de que, ao lê-las, retornes também tu à experiência que tiveste: as palavras suscitam, apenas provocam.' Mas como pode o pensamento, que é evidentemente invisível, tornar-se impresso no papel...? Observa então o papel. Resulta admirável se o pensarmos como um agregado monstruosamente grande de átomos, embora tuas mãos o tomam como uma unidade, pois ele se mantém agregado por uma força qualquer... estranho? Recorremos, então, à teorias que visam superar esta incômoda situação. Mas as teorias eliminam o estranhamento, ou apenas o repõe em outro contexto? Ora, se dissermos que existem forças intermoleculares ou forças de outros tipos, se observarmos a existência de leis naturais... tudo parecerá claro? Ou serão novas realidades hipostasiadas a estranhar? E, ainda, estranhar o próprio fato de fazermos teorias... estranhar, admirar 0 ato mesmo de existirmos.

Sente-te, neste momento. Sente a ti mesmo. Sente teu corpo, cada parte, o todo. Pensa neste teu pensamento. Vivencia esta presença de ti inteiramente em ti mesmo. ${ }^{2}$ Sente intensamente a presença das coisas todas que te cercam, sentindote ao mesmo tempo. Pensa na existência das coisas invisiveis ao teu redor: as ondas de rádio e tevê e outros tantos fenômenos físicos, inclusive ao nivel microfísico; num outro plano, o pensamento de alguma pessoa que possa estar ao teu lado, ou em algum lugar sabido; tua memória, que não percebes toda simultaneamente, mas está em ti, confunde-se com teu próprio ser; o tempo, que faz tudo escoar para um aparente nada...

Repentinamente, por força de um novo modo de ver, por força de uma nova disposição, as coisas do mundo, o próprio mundo, a nossa presença no mundo, tornam-se estranhas... percebemos, então, que temos, que somos este poder de recriar nosso contato com o ser, por uma atividade do nosso pensamento, observando a realidade de um modo inusitado, olhando além, olhando com carinho, espantando-nos, assombrando-nos, contemplando, admirando.

Conforme Santo Agostinho, em De Magistro.

O que o Idealismo Alemão denominou autoconsciência. Suscitamos, neste contexto, uma reflexão sobre a relação entre autosensiência e autoconsciência. 
Atentemos a este olhar além, que nos faz ser outros, quando então nos transformamos por uma ação que se origina em nosso interior. Atentemos a essa ação de considerarmos cada coisa e as coisas como um todo como se fosse a primeira ou a última vez. ${ }^{3}$ Quando o ver, o mirar é ação que sobrepassa o costume: "admiração".

Acontece, então, assim como com todas as palavras, que só poderás compreender o que digo se efetivamente puderes experimentar aquilo que dá significação a estas palavras. Então já serás outro e poderás reler tudo isto; e, quem sabe, retornar tuas idéias nas marcas do papel.

A admiração, o estranhamento é o modo de ver daquele que faz do filosofar um modo de viver.

Os gregos denominaram thaumátzein o comportamento originante do filosofar: Aristóteles: Metafísica A, 2, 17-19: "Porém o que põe um problema ou se admira, reconhece sua ignorância. (por isso também o que ama os mitos é de certo modo filósofo; pois o mito se compõe de elementos maravilhosos)" " Platão: Teeteto, 155d: "Isto demonstra que Teodoro não se equivocava ao te valorizar. Esse sentido do assombro é típico do filósofo. Pois a filosofia, com efeito, não tem outra origem e foi um bom genealogista aquele que fez que f́ris fosse a filha de tháumas".s.

\section{2 - Perguntar}

Todos os dias formulamos questões. Algumas têm um caráter eminentemente prático e visam solucionar problemas cotidianos. Outras, por sua vez, requerem uma visão mais abrangente e objetivam muito mais o conhecimento, mesmo que sem uma utilidade prática imediata. Entre estes dois procedimentos, os quais experimentamos cotidianamente, há evidentemente algo em comum. Mas o que seria? O que acontece, ao nivel do nosso pensamento, ao formularmos uma questão?

Não pretendemos uma resposta definitiva a este problema, mas avançar neste sentido, esperando que cada um descubra, também por meio de sua própria reflexão, algo que acontece em sua própria interioridade. Re-flectir: voltar-se sobre si mesmo, num processo infinito de des-velamento do nosso próprio ser e daquilo que denominamos mundo.

$\mathrm{O}$ ato de perguntar aparece-nos, num primeiro momento, como um movimento interior onde somos lançados no vazio, numa certa consciência dos limites de nosso conhecimento sendo, assim, processo e desejo de ultrapassagem daquilo que conhecemos e, portanto, daquilo que somos... Mas este "lançar-se no vazio", esta "ultrapassagem" de nossa própria condição representa apenas a perspectiva

\footnotetext{
Neste contexto, vide BORNHEIM, Gerd A. Introdução ao Filosofar. RJ: Globo, 1969.

"ho d'aporôn kaí thaumátzôn oíetai agnoeín (dió kaí ho filómythos filósofós poús estin ho gár mýthos sýnkeitai ek thaumasiôn)". (Metafisica, A, 2. Ed. Trilingüe por YEBRA, Valentín Garcia).

- "Theódôrs gáR, Ô FILE, FAÍNETAI OU KAKÓS TOPÁTZEIN PERÍ TÊS FÝSEOÚS SOU. Mála gár filosófou toúto tó páthos, tó thaumátzein 'ou gár állê archê filosofias ê haútê, kai éoiken ho tên Írin thaúmantos ékgonon fêsas ou kakôs genealogein" (Teet.155d. Conford. La Teoria Platônica del conocimiento. Barcelona: Paidos, 1983 e Teeteto. Paris: Ed. bilingüe Les Belles Lettres).
} 
de quem se põe no final de um processo, o qual pressupõe uma operação prévia e complexa.

O perguntar inclui sempre uma relação com um conhecimento já adquirido; a questão eleva-se sobre o que já sabemos em uma retomada que pressupõe uma unificação dos dados que possamos ter a respeito do objeto, da realidade perguntada. Ora, se pergunto "o que é isto?" ou "como fazer isto?" ou "Por quê...?", por exemplo, isso inclui que possa antes poder circunscrever aquilo que já sei sobre o perguntado, para indagar sobre o que não sei. Aliás, só posso efetivamente perceber que não sei algo sobre tal ou tal realidade ao reunir tudo o que já sei sobre a mesma.

Assim, o perguntar é um ato sintético, quando reunimos, unificamos nosso conhecimento sobre determinada realidade. Só por isso, o ato mesmo do perguntar representa já um conhecimento novo; por isso, o perguntar inclui em si já algo de resposta. Mas é ainda mais, pois além deste conhecimento novo, o qual consiste numa certa unificação do já sabido, inclui outro, a consciência do não sabido. Momento este em que a relação eu/mundo é posta em suspensão. Situamo-nos, então, nas fronteiras do que conhecemos e do qual temos uma certa decodificação ao nível da linguagem; percorremos nossos limites e lançamo-nos além, no vazio... ou melhor, lançamo-nos e somos lançados, arrebatados num gesto de entrega que, ao nos conduzir para fora de nosso universo conhecido, simultaneamente elabora um retorno à interioridade daquele que pergunta. Perguntar é estar inteiramente em si e, por isso, além de si, "suspenso".

Somos lançados além... pois é a misteriosa presença daquilo que nos cerca e ultrapassa, este "situar-se" em meio aos fenômenos que decorrem no tempo e no espaço, o motivo de um sentir faltar. Ora, se estivéssemos tão-só em nós mesmos e o ser fosse expressão de nossa interioridade (e essa é a tese do idealismo subjetivo), não haveria motivos que nos conduzissem além; bastarmo-nos-íamos, e nos restaria calar. Há, pois, um contato com o mundo, uma experiência, uma vivência no interior do surgimento de toda questão. Perguntar é, desse modo, a atitude de quem vivencia o mundo por meio de uma retomada simultânea de si mesmo em tal relação; gesto de confluência que requer a síntese, sempre de novo reposta, entre o nosso interior e o mundo exterior.

A vivência, o contato com os fenômenos do mundo nos perturba e motiva; angustia e articula sentido; envolve-nos no estranhamento por via de um entranhamento do mundo no eu e do eu no mundo. Perguntar é "situar-se" na unidade abrangente da vida e da história.

A própria formulação de uma questão inclui sempre a busca de uma unidade; unidade que se funde com a vivência do mundo e reclama sentido. Mas também unidade em outra acepção, unidade lógica, quando elaboramos as conexões necessárias que se estabelecem entre os objetos do mundo e, mais além, entre 0 meu conhecimento de tais objetos e seu ser, entre o conhecimento e o ser. $\mathrm{Na}$ confluência entre a vivência e a lógica, enquanto visa à totalidade, o perguntar torna-se filosofar.

As questões multiplicam-se, entrecruzam, reclamam a unidade perdida. Surge, então, a necessidade e a carência de um elo que re-ligue o eu e o mundo. E, 
do interior de tal oniabrangência, deverá o eu re-ligar-se a si mesmo e ao outro. 0 nascimento do filosofar em cada um coincide com a emergência de um novo modo de perguntar o qual, sendo expressão do gesto primordial de admiração, é um convite e aguarda do outro a resposta.

\section{3 - Dialogar}

Desde que o perguntar se dirija ao outro, exercendo-se assim a dimensão intersubjetiva de sua significação, torna-se convite ao diálogo. E, se por um certo impulso, que nos situa com relação à Filosofia e ao filosofar, como forma de envolvimento com a própria vida, aceitemos e retornemos o convite, talvez então possamos nos alçar a uma esfera mais elevada, ou seja, à disposição ao convívio. No movimento que conduz do convite à aceitação e retorno do convite, elevando-se à con-vivência, poderemos observar, de uma posição privilegiada, a dialética inerente à condição de diálogo, o que, de algum modo, situa nossas presenças e o tempo compartido num exercício conjunto de conexão entre vida e pensamento. ${ }^{6}$ A dialética da filesis, antifilesis e filía, exposta pelo prof. Cirne-Lima, reclama, na versão exposta em nossa reflexão anterior, o sentido da relação entre vida, pensamento, história e filosofia.

Mas, qual o sentido de perguntar por uma conexão entre vida, pensamento, história e filosofia?

Compreendo que, desde que nos disponhamos ao convívio e ao diálogo, situamo-nos no interior de um movimento, no qual a inter-relação entre o diálogo interior e o diálogo exterior expressa a dinâmica e a intensidade de nosso tempo compartido. Observemos, deixemo-nos envolver por esta dinâmica, que nos situa nas palavras, neste tempo em que con-vivemos, o que nos remete para além das próprias palavras. Desta posição, que é simultaneamente exercício de conexão entre vida e pensamento, entre nossas histórias individuais e uma história coletiva, situando-nos no interior e, simultaneamente, além das palavras, talvez possamos exercitar o estranhamento, a admiração inerente a uma re-flexão que busca o convívio. Tal atitude, dada na admiração frente à pura presença de si para outro, talvez possa suscitar a disposição e, portanto, a possibilidade do próprio convivio.

Mas o convívio requer um segundo princípio, i. é, um começo que nos situe nas palavras; e este começo, como já dizíamos anteriormente, é um convite, o qual requer um modo especial de expressão, capaz de nos situar em movimento dialógico: o lógos do perguntar.

Buscávamos, há pouco, o sentido de perguntar por uma conexão entre vida, pensamento, histónia e filosofia. Observamos, então, que o ato mesmo do perguntar nos situa em uma dupla perspectiva, conectando a esfera do diálogo, dinâmica que envolve a esfera interior e a esfera exterior de nosso convívio e nos situa nas palavras, com um estranhamento, uma admiração que nos situa além das próprias palavras e se vincula à nossa disposição. Observamos que o perguntar é convite, é começo e requer do outro uma atenção expressa primordialmente na

- Os motivos de tal reflexão remetem à dialética da filesis, antifilesis e filía, exposto pelo prof. CirneLima, em Dialética para Principiantes, Porto Alegre: Edipucrs, 1995, p. 20-22. 
disposição ética do ouvir. Isso suscita, em mim, uma reflexão sobre o sentido de uma dialética cujo movimento primeiro encontra, no diálogo, o momento sintético da relação entre o estranhamento ou admiração' e o lógos do perguntar.

Pretendi partir de um horizonte, o qual situava o convite, a aceitação e o retorno do convite, na expectativa de um convivio, para buscar, no envolvimento com nossa situação, a dialética inerente ao próprio filosofar. Mas o que acabamos por encontrar não é mais que uma perspectiva possivel de compreender o nosso próprio gesto. E digo isso porque talvez o nosso diálogo possa elevar-se à perspectiva da História da Filosofia, o que implica em um sentido outro à própria pergunta, sempre de novo reposta, "o que é Filosofia"?

Ao partirmos de uma perspectiva que pretendia relacionar vida, pensamento, história e filosofia fomos remetidos ao próprio gesto, o qual pretendia uma postura filosofante com relação ao problema apresentado. No interior deste gesto, no envolvimento de cada um com este gesto, pretendíamos encontrar um movimento no qual observássemos a confluência entre a nossa vida e a Vida, o nosso pensamento e o Pensamento, a nossa história e a História, a Filosofia e o nosso filosofar. E se pudermos, com isso, refletir sobre o sentido de a Filosofia ser um modo de viver, sobre o qual ensaiamos a dialética entre o admirar e o lógos do perguntar, vislumbrando assim o momento sintético do diálogo, então, segundo penso, poderemos transitar à compreensão da relação do nosso próprio gesto e a História da Filosofia.

Trata-se do sentido e da possibilidade de estabelecermos um diálogo com a História da Filosofia. Trata-se da dialética da relação estabelecida entre o nosso perguntar e as questões a partir das quais possamos estabelecer uma certa continuidade entre os pensamentos dos filósofos, no decorrer da História da Filosofia. Só há sentido em falar em uma História, com relação à Filosofia, se pudermos estabelecer esta unidade. Deixemos de lado, no entanto, provisoriamente, a questão sobre o sentido necessário ou contingente (ou, dito de outro modo, temporal ou atemporal) desta unidade da História; isso porque tal questão simultaneamente demarca o próprio sentido de se falar em História, assim como também deve ser historicamente compreendida. Deixemos de lado, ainda provisoriamente, a questão sobre se a História da Filosofia deva ser assimilada a partir de uma perspectiva mais ampla, que transcenda a própria Filosofia (por exemplo, a partir da História, como tal, ou mesmo a partir da Biologia), sem que, com isso, deixemos de fazer Filosofia. Concentremo-nos, primeiramente, no problema anteriormente apresentado, que demarca o problema da relação entre o nosso filosofar e a História da Filosofia. É possivel alguma relação, um diálogo com essa História sem que nos ponhamos, desde já, a filosofar? E é possível filosofar sem que nos situemos, desde já, em alguma relação com esta História?

O primeiro movimento dialético, o qual relacionava o admirar e o perguntar no interior do diálogo, opera um novo movimento, onde os momentos antitéticos reclamam uma sintese, na qual estamos completamente envolvidos e reclama o sentido ético-político de nossa relação com a História.

Que, em Platão e Aristóteles, é expresso pelo verbo thaumátzein. 